\title{
Spatial distance effects on incremental semantic interpretation of abstract sentences: Evidence from eye tracking ${ }^{\text {th }}$
}

\author{
Ernesto Guerra*, Pia Knoeferle \\ Cognitive Interaction Technology Excellence Cluster \& Department of Linguistics, Bielefeld University, Germany
}

\section{A R T I C L E I N F O}

\section{Article history:}

Received 21 February 2013

Revised 15 July 2014

Accepted 22 July 2014

Available online 14 September 2014

\section{Keywords:}

Abstract sentences

Spatial distance

Visual context

Reading

Eye tracking

\begin{abstract}
A B S T R A C T
A large body of evidence has shown that visual context information can rapidly modulate language comprehension for concrete sentences and when it is mediated by a referential or a lexical-semantic link. What has not yet been examined is whether visual context can also modulate comprehension of abstract sentences incrementally when it is neither referenced by, nor lexically associated with, the sentence. Three eye-tracking reading experiments examined the effects of spatial distance between words (Experiment 1) and objects (Experiment 2 and 3 ) on participants' reading times for sentences that convey similarity or difference between two abstract nouns (e.g., 'Peace and war are certainly different...'). Before reading the sentence, participants inspected a visual context with two playing cards that moved either far apart or close together. In Experiment 1, the cards turned and showed the first two nouns of the sentence (e.g., 'peace', 'war'). In Experiments 2 and 3, they turned but remained blank. Participants' reading times at the adjective (Experiment 1: first-pass reading time; Experiment 2: total times) and at the second noun phrase (Experiment 3: first-pass times) were faster for sentences that expressed similarity when the preceding words/objects were close together (vs. far apart) and for sentences that expressed dissimilarity when the preceding words/objects were far apart (vs. close together). Thus, spatial distance between words or entirely unrelated objects can rapidly and incrementally modulate the semantic interpretation of abstract sentences.
\end{abstract}

(c) 2014 Elsevier B.V. All rights reserved.

\section{Introduction}

\subsection{Visual information and the comprehension of concrete} language

More than a decade after Tanenhaus, Spivey-Knowlton, Eberhard, and Sedivy (1995) reported rapid visual context effects on syntactic structuring during spoken language

\footnotetext{
The data presented in this manuscript were also reported in the form of a thesis in partial fulfilment of the requirements to obtain a doctoral degree (EG).

* Corresponding author. Address: FBIIS, CITEC, Inspiration 1, Bielefeld University, D-33615 Bielefeld, Germany. Tel.: +49 (0) 52110612117 .

E-mail address: ernesto.guerra@uni-bielefeld.de (E. Guerra).
}

comprehension, the cognitive sciences abound with eyetracking research into how real-time language comprehension relates to visual perceptual processes (e.g., Ferreira, Apel, \& Henderson, 2008; Hartsuiker, Huettig, \& Olivers, 2011; Richardson, Altmann, Spivey, \& Hoover, 2009 for relevant discussion). For concrete language, eye-tracking evidence suggests that referential visual context can inform incremental semantic interpretation (Sedivy, Tanenhaus, Chambers, \& Carlson, 1999) as well as syntactic structuring (Tanenhaus et al., 1995); that experience-based object affordances can guide structural disambiguation (e.g., Chambers, Tanenhaus, \& Magnuson, 2004); and that depicted clipart events can disambiguate locally syntactically ambiguous utterances (e.g., Knoeferle \& Crocker, 2006; Knoeferle, Crocker, Scheepers, \& Pickering, 2005). 
In addition, action-verb incongruence can rapidly modulate sentence comprehension during reading (Knoeferle, Urbach, \& Kutas, 2011). In all of these studies, objects and actions in the visual context were referenced by language.

A number of eye-tracking studies have furthermore shown that objects which are not mentioned but which are semantically related to a target word attract more visual attention than semantically unrelated objects (e.g., Huettig \& Altmann, 2005; Huettig, Quinlan, McDonald, \& Altmann, 2006; Mirman \& Magnuson, 2009); that phonological competitors (words that begin with the same syllable as the target) compete for attention with the target during early stages of referential processing (Allopenna, Magnuson, \& Tanenhaus, 1998); and that more visual attention goes to objects that share the color or shape of a target referent than to unrelated objects (see Dahan \& Tanenhaus, 2005; Huettig \& Altmann, 2011; Huettig \& McQueen, 2007). In sum, visual context can rapidly interact with the real-time comprehension of concrete language in the presence of a referential (a word refers to an object) or lexical-semantic (a word is semantically associated with an object) link.

In parallel, it has been found that other visual features can modulate language processing even when they are not explicitly mentioned but implied by language (e.g., Kaschak et al., 2005; Meteyard, Zokaei, Bahrami, \& Vigliocco, 2008; Pecher, van Dantzig, Zwaan, \& Zeelenberg, 2009; Stanfield \& Zwaan, 2001; Zwaan, Stanfield, \& Yaxley, 2002). In a picture-verification task, participants' response times were longer when the shape or orientation implied by the sentence (e.g., He hammered the nail into the floor) mismatched (a horizontal nail) than when it matched (a vertical nail) the picture of a nail (Stanfield \& Zwaan, 2001; Zwaan et al., 2002). More recent findings have shown that the orientation of visually-presented objects can modulate reading times for sentences that implied the same (vs. a different) object orientation (Wassenburg \& Zwaan, 2010). Other studies have investigated even subtler relationships between linguistic and non-linguistic information. For instance, Kaschak et al. (2005) reported that participants were slower in a sentence sensibility judgment task when motion described by a sentence was in the same (vs. the opposite) direction as simultaneously presented visual motion. In another study, Meteyard et al. (2008) found that low-level visual motion modulated lexical-decision times. Decision times were slower when motion words were incongruous (vs. congruous) with visual motion.

\subsection{Visuo-spatial representations and abstract concepts: spatial distance and semantic similarity}

The studies discussed above examined the processing of concrete words or sentences that were either explicitly or implicitly linked to aspects of the visual context. In these cases it is arguably not surprising that visual context influences language comprehension rapidly and incrementally. What psycholinguistic research has not yet examined in detail is whether visual context effects are even more per- vasive and could extend to abstract language comprehension.

Unlike concrete concepts, abstract concepts are not explicitly related to perceptual experience. In fact, some theories argue for a fundamental difference between concrete and abstract representations. The Dual Coding Theory (Paivio, 1986, 2013) proposes that concrete language is represented both at the linguistic level (through associations with other words) and at the perceptual level (through associations created during direct interaction with objects). By contrast, abstract language is represented only at the linguistic level, via associations with other words (see also Crutch \& Warrington, 2005). Other theories, by contrast, would assume that abstract concepts are represented at the perceptual level, too, but in a more implicit manner compared to concrete concepts. Conceptual Metaphor Theory (Lakoff \& Johnson, 1980, 1999), for instance, argues that abstract concepts such as similarity are structured and understood through metaphorical mapping from perceptual and motor experience (e.g., of spatial closeness), see (1) for examples:
a. Your ideas are close to mine.
b. My aims in this company are far from yours.
c. I can't tell the two theories apart.

What the examples in (1) reveal is that speakers use concrete spatial concepts (e.g., close, apart, far) when talking about more abstract ideas (e.g., similarity; see Lakoff, Espenson, \& Schwartz, 1991 for a compilation of similar expressions). Lakoff and Johnson (1980) interpreted these expressions as metaphorical, reflecting a relation between concrete (source) and abstract (target) domains. Consequently, concepts lacking direct experiential correlates (e.g., similarity) are assumed to be metaphorically mapped onto more concrete representations (e.g., closeness) that can be directly experienced. This hypothesis can generate predictions about the potential role of visually-based representations in abstract language comprehension: When the concept of semantic similarity is activated, the representation of closeness should also be active; and when the concept of semantic dissimilarity is active, one might expect the representation of spatial distance to be active, too (e.g., Gallese \& Lakoff, 2005). ${ }^{1}$

Casasanto (2008) tested this hypothesis by asking participants to rate the similarity between abstract nouns (Experiment 1) and unknown faces (Experiment 2), all of which were presented either far apart or close to each other on a computer screen. When abstract words were presented close to each other (vs. far apart), they were rated as more similar. Ratings for faces were also modulated by spatial distance but showed the opposite pattern: Faces were rated as more dissimilar when presented close together (vs. far apart). In a related study, Boot and Pecher (2010) asked participants to perform speeded judgements

\footnotetext{
1 Note that the present study is not aimed at testing the assumptions of Conceptual Metaphor Theory (i.e., how relations between spatial distance and semantic similarity emerge). Instead, we informed our hypothesis about potential links between visual information and abstract language from Conceptual Metaphor Theory.
} 
on whether two squares were similarly or differently colored. Response times were shorter when colored squares were similar and close to each other (vs. far apart), and when differently-colored squares were far apart (vs. close to each other). Together, Boot and Pecher (2010) and Casasanto's (2008) findings suggest that representations of spatial distance are mapped onto the more abstract concept of similarity and that this mapping modulates offline behavioral measures.

By contrast, evidence for the role of perceptual representations in abstract language comprehension is mixed. A reaction time study (Richardson, Spivey, Barsalou, \& McRae, 2003) showed that the orientation (vertical vs. horizontal) implied by both concrete (e.g., to sink) and abstract (e.g., to hope) sentential verbs modulated response latencies in an object discrimination task (whether a presented object was a square or a circle, Experiment 1). When an abstract verb implied a vertical orientation (e.g., to hope), response times were faster for horizontally than vertically aligned objects; when the verb implied a horizontal orientation (e.g., argued with), response times were faster for objects presented on the vertical (vs. horizontal) axis. Subsequent research with the same task, however, has replicated these results for concrete verbs only (Bergen, Lindsay, Matlock, \& Narayanan, 2007). It is thus unclear whether perceptual information interacts with comprehension when language is abstract and when there are no referential or lexical-semantic links.

\subsection{The present study}

The present paper contributes to this burgeoning area of research by investigating (a) whether, and if so, to which extent, spatial distance between objects can modulate real-time semantic interpretation of abstract sentences; and (b) whether information from the non-linguistic visual context can modulate language comprehension even in the absence of referential or lexical-semantic links. Participants inspected a visual context showing two objects (playing cards) moving close together (or farther apart) and subsequently read an unrelated sentence about two abstract nouns described as either semantically similar (e.g., 'battle and war are similar') or dissimilar ('peace and war are dissimilar'). We examined whether card distance could prime ${ }^{2}$ the comprehension of semantic similarity and dissimilarity. By recording people's eye movements during sentence reading, we were able to observe the time course of this potential priming process.

Current accounts of visually situated language comprehension (e.g., Altmann \& Kamide, 2009; Knoeferle \& Crocker, 2006, 2007) predict rapid visual context effects but are underspecified with regard to their representational assumptions. Thus, they are compatible with, but do not predict, rapid integration of perceptual and concep-

\footnotetext{
2 'Priming' is often used to refer to the advantage of processing a word (the target), after a previously- or concurrently-processed associated word (the 'prime', e.g., Anderson \& Pirolli, 1984; Collins \& Loftus, 1975; Meyer \& Schvaneveldt, 1971). We use the term priming in a wider sense including clauses, sentences and pictures (cf. Connell \& Lynott, 2012; Coppens, Gootjes, \& Zwaan, 2012).
}

tual representations, such as spatial distance, and semantic similarity. Conceptual Metaphor Theory (Lakoff \& Johnson, 1999), by contrast, motivates the link between spatial distance representations and semantic similarity but makes no predictions about the time course of any such effects during real-time sentence comprehension. Integrating mappings such as from spatial distance to semantic similarity into accounts of visually situated comprehension (e.g., the Coordinated Interplay Account, Knoeferle \& Crocker, 2006, 2007) would allow us to make predictions about the effects of visually-derived representations on the semantic interpretation of abstract concepts and the time course of such potential effects.

We predict that if the visually-derived representation of spatial distance is pre-activated (via presentation of objects far apart or close together), it should prime the processing of ensuing abstract linguistic representation of semantic similarity. Specifically, we should see rapid effects of distance on the processing of semantic similarity during comprehension. These effects should appear closely time-locked to regions of the sentence in which semantic similarity becomes available. This prediction is motivated by the close temporal coordination between visual perceptual processes and the comprehension of (concrete) language that has informed accounts of visually situated language comprehension (see Knoeferle \& Crocker, 2006, 2007).

There are at least two possibilities for how precisely spatial distance could prime the processing of semantic similarity. One possibility is that a representation of distance activates the concept of closeness, and such activation spreads to the associated abstract concept of similarity (cf. Mahon \& Caramazza, 2008). This should result in a local processing advantage at the sentence region which is lexically-associated with "close" or "far". Such local effects could be explained by a simple priming account. Alternatively, effects of spatial distance could appear in multiple regions of the sentence, including regions where semantic similarity is not explicitly mentioned but instead implied by conjoined words. Such effects would seem to implicate compositional processes and could not be straightforwardly explained by simple lexical-semantic priming (see Knoeferle et al., 2011, for a similar argument). Whether priming or compositional in nature, to the extent that effects of spatial distance on semantic similarity interpretation are rapid and incremental, situated language processing accounts will want to accommodate them.

In three eye-tracking experiments participants inspected a visual context (two playing cards depicted as moving apart from one another vs. close together) and subsequently read a sentence about abstract ideas that were either similar (e.g., 'Battle and war are surely similar...') or dissimilar (e.g., 'Peace and war are certainly different...'). We varied between the experiments to which extent the visual context and the sentence were related; in this way we assessed visual context effects both when there was and when there was not an overt relation between the visual context and language. In Experiment 1, cards on critical trials presented two abstract nouns that re-appeared in the ensuing sentence. In Experiment 2, cards on critical tri- 
als were blank, but participants learnt the pairing of the abstract nouns in blocks, prior to reading the sentences. In Experiment 3, only blank cards were shown, thus eliminating any relation other than temporal contiguity between the visual context and the subsequent sentence.

\section{Experiment 1}

Recent evidence from a similarity-judgment study shows that two randomly paired written abstract words presented far apart were judged as less similar semantically compared to when the same words were presented close together (Casasanto, 2008, Experiment 1). In our first experiment we asked whether the effect of spatial distance extends to real-time comprehension during sentence reading. Participants inspected a visual context presenting two cards moving either close together or far apart. The cards had either two semantically similar or dissimilar abstract nouns written on them. Immediately after the card context, participants read a sentence containing the two nouns displayed on the cards and judged sentence veracity based on their world knowledge. If spatial distance effects generalize from similarity judgments to sentence comprehension, we should observe shorter reading times for sentences expressing dissimilarity and similarity between the two abstract nouns when the preceding words-oncards were far apart and close to each other, respectively. Moreover, if spatial distance affects semantic interpretation incrementally, these effects should emerge at the point in the sentence where the relation between the two words is made explicit (either similar or dissimilar), namely the adjective region. Potentially, spatial distance effects could emerge even earlier, since at the and-coordination of the first two sentential nouns either semantic similarity or dissimilarity was already implied. Spatial distance effects at the conjoined nouns would suggest simple priming is not sufficient to accommodate the results. Finally, observing these effects in early reading time measures such as first-pass time or regression path duration, would suggest they are rapid; alternatively, spatial distance effects could appear in later measures, such as total times or later (post-adjective) in the sentence.

\subsection{Method}

\subsubsection{Participants}

Thirty-two native speakers of German (mean age: 23.6; range: 19-33 years old) with normal or corrected-to-normal vision from the Bielefeld University community received each 6 Euros for participation. None of them had been exposed to a second language before age 6 . All participants gave informed consent.

\subsubsection{Materials and design}

The visual context for experimental trials showed the images of two playing cards, each sized $155 \times 265$ pixels with a blue playing-card design on one side, and an abstract noun (e.g., 'peace', 'war') in black font (12 pts.) on its gray front side (see Fig. 1). For experimental trials, we manipulated whether the cards (and thus the words a
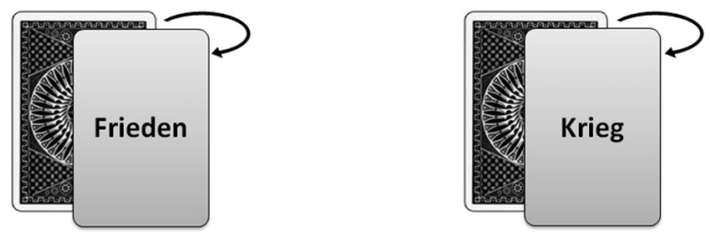

b

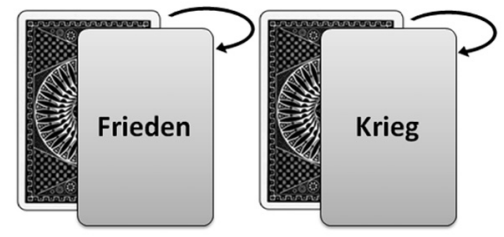

C
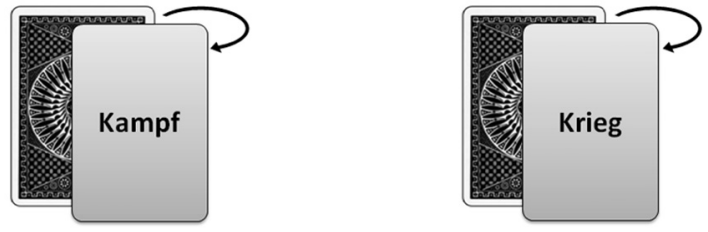

d

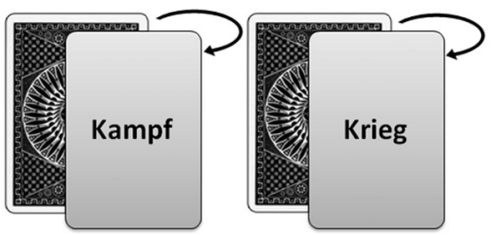

Fig. 1. Example of visual contexts for the sentences in Table 1. Cards appeared on the screen showing their backside and turned, as indicated by the arrow, to present the two first sentential nouns in Experiment 1.

on them) were close together (the two cards moved from their initial middle position close to each other) or far apart (the two cards moved from their initial position far apart from each other).

To inform construction of the sentences for the eyetracking experiment, a different group of participants $(n=16)$, rated pairs of abstract nouns $(n=240)$ on a scale from 1 to 7 for their semantic similarity. Sixty pairs were synonymous and 120 antonymous, plus 30 related and 30 unrelated pairs as fillers. From these we selected the 48 noun pairs with the highest inter-rater consensus ${ }^{3}$ and constructed coordinated noun phrase sentences that either expressed dissimilarity (e.g., 'Peace and war are certainly different, suggested the anthropologist') or similarity (e.g., 'Battle and war are surely similar, suggested the anthropologist'). Words that differed between the sentences within an item (the first noun phrase, the adverb and the adjective) were matched for number of characters and frequency. ${ }^{4}$

\footnotetext{
${ }^{3}$ Item 48 in all three experiments and item 47 in Experiments 1 and 3 were removed from the analysis due to an error in the order of word presentation (see Appendix A).

${ }^{4}$ Two paired sample $t$-test revealed no significant differences between the frequencies of the two groups of words or their length (both $t$-values $(48)<2, p$-values $>$.05)
} 
Table 1

Example item sentences and the four conditions.

\begin{tabular}{|c|c|c|}
\hline Image & Sentence & Condition \\
\hline Fig. 1a & $\begin{array}{l}\text { Frieden }_{N P 1} \text { und }_{\text {coord. }} \text { Krieg }_{N P 2} \text { sind }_{V P 1} \text { bestimmt }_{A D V} \\
\text { verschieden } \\
A D J \text {, das verriet VP2 der Anthropologe }\end{array}$ & Far-Dissimilar \\
\hline Fig. 1b & $\begin{array}{l}\text { Frieden }_{N P 1} \text { und }_{\text {coord. }} \text { Krieg }_{N P 2} \text { sind }_{V P 1} \text { bestimmt } \\
\text { verschieden }_{A D J} \text {, das verriet } \\
V P 2\end{array}$ & Close-Dissimilar \\
\hline Fig. 1c & $\begin{array}{l}\text { Kampf }_{N P 1} \text { und }_{\text {coord. }} \text { Krieg }_{N P 2} \text { sind }_{V P 1} \text { freilich }_{A D V} \\
\text { entsprechend }_{A D J} \text {, das verriet } \\
V P 2 \text { der Anthropologe }\end{array}$ & Far-Similar \\
\hline Fig. 1d & $\begin{array}{l}\text { Kampf }_{N P 1} \text { und }_{\text {coord. }} \text { Krieg }_{N P 2} \text { sind }_{V P 1} \text { freilich }_{A D V} \\
\text { entsprechend }_{A D J} \text {, das verriet } \\
V P 2 \text { der Anthropologe }\end{array}$ & Close-Similar \\
\hline
\end{tabular}

Translation. Dissimilar sentence: 'Peace and war are certainly different, suggested the anthropologist'; Similar sentence: 'Battle and war are surely similar, suggested the anthropologist'.

Together the visual context (Close or Far) and sentence levels (Similar or Dissimilar) resulted in four experimental conditions: Cards close to each followed by a sentence that expressed similarity (Close-Similar); cards close to each other followed by a sentence that expressed dissimilarity (Close-Dissimilar); cards far apart followed by a sentence that expressed similarity (Far-Similar); and cards far apart followed by a sentence that expressed dissimilarity (FarDissimilar, see Table 1).

We used a Latin square design to assign items and experimental conditions to each participant: Four lists were created, each of which contained the same number of trials per condition and every item in only one condition. In addition each list contained 96 filler trials (144 trials in total); 24 of the fillers displayed nouns on their front side and 72 had blank fronts. The visual context was similar to the experimental trials varying either in the final position of the two playing cards (e.g., top corners vs. bottom corners) or the color of them (e.g., red cards). Trial presentation was pseudo-randomized such that all experimental sentences were either preceded by one, two or three fillers, and never by another experimental item.

\subsubsection{Procedure}

Participants' eye movements were recorded using an Eyelink 1000 desktop head-stabilized tracker (SR Research). At the beginning of the session, a 9-point calibration procedure was carried out, and during the experiment additional recalibration was performed when necessary. After the calibration, participants were presented 14 practice trials. Following the practice trials the experiment began. Each trial was initiated by the experimenter, once participants fixated a black dot in the middle of the screen. Fig. 2 depicts the temporal order of an experimental trial.

Every trial consisted of three main steps: In step 1 (Fig. 2a), two playing cards (with their backside displayed) appeared at the bottom of the display and moved upwards to the middle of the screen. For experimental trials, cards then moved along the horizontal axis such that their final position was either far apart or close together (see Fig. 1). After reaching their final position, the cards turned and showed each an abstract written noun for $4000 \mathrm{~ms}$ for all experimental trials and a third of the filler trials. For the remaining 72 fillers the cards turned and showed a blank front for $500 \mathrm{~ms}$. Participants were instructed to carefully look at the cards and remember them. In step 2 (Fig. 2b), a black dot appeared for $1000 \mathrm{~ms}$ at the position where a subsequent sentence started. Participants were asked to focus on the black dot, carefully read the sentence and then judge sentence veracity based on their world knowledge by pressing a yes or a no button (Cedrus Response Pad 8Buttons, Large). In the third and final step, participants inspected a static picture of two playing cards (Fig. 2c), and verified whether the two playing cards matched or mismatched the final position of the two playing cards they saw before reading the sentence. Participants pressed a yes-button when cards matched and a no-button when cards mismatched.

\subsection{Data analysis}

Before the inferential analyses, contiguous fixations below $80 \mathrm{~ms}$ duration were merged. Isolated fixations $<80 \mathrm{~ms}$ that could not be merged with other fixations or fixations $>1200 \mathrm{~ms}$ were excluded (see, e.g., Sturt, Keller, \& Dubey, 2010). Furthermore, we removed trials with an incorrect response from the analysis. Critical sentences had eight different areas of interest as in (2). The main region of analysis was the adjective (ADJ) region in which the relation between the two abstract nouns was explicitly mentioned. We further examined the second noun phrase (NP2) for possible earlier effects, and the second verb phrase (VP2) and the third noun phrase (NP3), to see whether predicted effects could extend to later sentence regions.

(2) Frieden $_{N P 1} \mid$ und $_{\text {coord. }}\left|\operatorname{Krieg}_{N P 2}\right| \operatorname{sind}_{V P 1} \mid$ bestimmt $_{A D V} \mid$ verschieden $_{A D J}$, $\mid$ das verriet $_{\text {VP2 }} \mid$ der Anthropologe NP3. $_{\text {. }}$. Peace $_{\mathrm{NP1}} \mid$ and $_{\text {coord. }} \mid$ war $_{\mathrm{NP2}} \mid$ are $_{\mathrm{VP1}} \mid$ certainly $_{\mathrm{ADV}}$ | different $_{\mathrm{ADJ}}$, | suggested $_{\mathrm{VP2}} \mid$ the anthropologist $\mathrm{NP}_{\mathrm{N} 3}$,

Using the Data Viewer software (SR Research) we computed first-pass time, regression path duration and total reading time. First-pass time is the sum of all fixation durations in an analysis region prior to moving to another region. Regression path duration is the sum of all fixation durations from first entering a region until moving to the right of that region; unlike first-pass time it includes reading time following regressions out of the region (see, e.g., Konieczny, Hemforth, Scheepers, \& Strube, 1997; Liversedge, Paterson, \& Pickering, 1998; Rayner, 1998; 


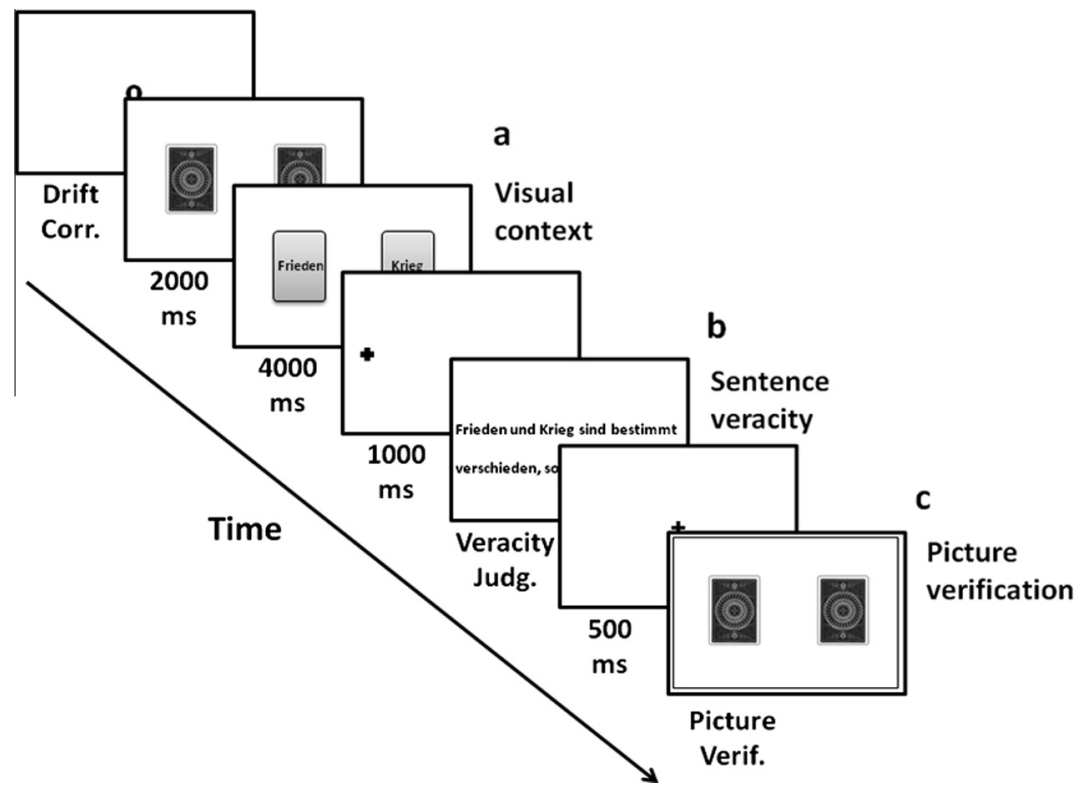

Fig. 2. Schematic representation of an experimental trial for Experiment 1.

Traxler, Pickering, \& Clifton, 1998). Finally, total reading time is the duration of all fixations in a given region (Rayner, 1998; Rayner \& Liversedge, 2004).

Kolmogorov-Smirnov normality tests confirmed that the data was positively skewed and significantly diverged from the normal distribution for all regions and conditions. Thus, the raw data were log-transformed prior to inferential analysis to improve normality of the distribution (e.g., Tabachnik \& Fidell, 2007, 246f.). Extreme data points for each interest region in each condition were further removed if their deletion improved normality $(2.5 \%$ of the overall data and no more than $5 \%$ of the cases per condition). Removal of extreme cases and log-transformation improved skewness and kurtosis, leading to non-reliable Kolmogorov-Smirnov statistics (KS ps>.05), with the exception of the NP2 region.

A linear mixed-effect regression analysis (lme4 R) was conducted on log-transformed reading times data. Mixed models are useful in analyzing psycholinguistic data since these models allow simultaneous inclusion of crossed random factors for participants and items as an alternative to quasi- $F$ and separate by-participants by-items analysis ( $F 1, F 2$ analyses). They can also model participant and item variation around the fixed effects by including random slopes for participants and items. Furthermore, mixed models are robust against missing values and do not require homoscedasticity and sphericity assumptions to be met (Baayen, Davidson, \& Bates, 2008; Barr, 2008; Quené \& van den Bergh, 2004, 2008). The analysis produces estimates, standard errors and $t$ values for all main and interaction fixed effects. To evaluate significance we used the criteria of an absolute value of $t>2$ (Baayen, 2008).
The two factors and their interactions (i.e., spatial distance and semantic similarity) constituted the fixed effects in our mixed model. We centered the factors using a scale function ${ }^{5}$ in $\mathrm{R}$ to minimize collinearity between them. This function centers the data on a mean of 0 and a range of 2 . Both participants and items were included as crossed random intercepts and we always included all random slopes justifiable by our experimental design. ${ }^{6}$ The omission of random slopes in linear mixed-effects regressions has been discussed as anti-conservative (Sturt et al., 2010), and is thought to increase the risk of Type I errors (Barr, Levy, Scheepers, \& Tily, 2013). The R-code for the full model was the following: $\operatorname{lmer}\left(\mathrm{dv} \sim \mathrm{iv} 1{ }^{*} \mathrm{iv} 2\right.$ $+(1+\mathrm{iv} 1 *$ iv2 | participant $)+(1+\mathrm{iv1}$ * iv2 | item $)$, data $)$. The "dv" in the R-code represents the dependent variable (for instance, first-pass time), and "iv1" and "iv2" represent the two independent variables (i.e., spatial distance and semantic similarity). This model includes fixed effects for the two factors, the interaction between them, participants and items as random intercepts, and both main and interaction effects as random slopes for both random intercepts.

Whenever the full model did not converge, we followed the recommendations by Barr et al. (2013). We began by increasing the number of iterations in the estimation procedure, which resulted in convergence for most of our models. When this strategy was not effective, we simplified the model's random effects structure (see Barr et al.,

\footnotetext{
${ }^{5}$ (data\$factor=scale(as.numeric(data\$factor)).

${ }^{6}$ For measures in which we found interaction effects with the linear mixed-effect regression we also performed $2 \times 2$ repeated measures ANOVAs by participants and items. These support the conclusions from the linear mixed-effects regression analyses (see Table B1 in Appendix B).
} 
2013) by removing random effects correlations for participants and items. ${ }^{7}$ For those regions and measures in which we observed a reliable interaction of the factors we also report pairwise comparisons. These consisted of a full linear mixed-effect regression on the influence of spatial distance for either (a) sentences that expressed similarity, or (b) sentences that expressed dissimilarity between abstract nouns. These analyses permit detailed insight into spatial distance effects within a sentence condition; nevertheless they suffer from a loss of power due to splitting the data. Moreover, our within-subject within-item design is aimed to reveal interaction effects, if they exist.

\subsection{Results}

Table 2 shows mean reading times in milliseconds per condition, for all measures and regions analyzed. Results of the linear mixed-effect regression analyses are presented in Table 3. Fig. 3 illustrates the interaction effect between spatial distance and semantic similarity. At the NP2 region no reliable effects were observed. At the critical adjective region (ADJ), a pervasive similarity main effect emerged in all measures: reading times were shorter for sentences expressing similarity compared to those expressing dissimilarity (all $t s>2.63$ ). As predicted, we found a reliable interaction between spatial distance and semantic similarity $(t=-2.08)$ in first-pass reading time at the ADJ region. Reading times were shorter when similarity-conveying sentences were preceded by cards-with-words presented close to each other (vs. far apart) and reading times for sentences that conveyed dissimilarity were shorter when preceded by cards-with-words presented far apart (vs. close to each other; all other $t s<|2|$ ). Reliable interaction effects emerged also at the VP2 and NP3 regions in first-pass reading times $(t=-2.09$ and $t=-2.39$, respectively) and in total reading times at NP3 $(t=-2.58)$, all of them with the same gaze pattern as for the $\mathrm{ADJ}$ region.

Finally, we explored the observed pattern of interaction using pairwise comparisons. For first-pass reading times at the $\mathrm{ADJ}$ region, pairwise comparison showed a reliable effect of spatial distance for sentences expressing similarity only $(t=2.05$; sentences expressing dissimilarity: $t<1$ ). By contrast, for the VP2 we found a marginally significant effect of distance for sentences that expressed dissimilarity only $(t=-1.97)$. Similarly, at the NP3 reliable spatial distance effects were found only for sentences that expressed dissimilarity (first-pass reading times: $t=-2.77$ and total reading times: $t=-2.84$; for sentences expressing similarity: $t<1$ in both measures).

\subsection{Discussion}

In our first experiment, we observed spatial distance effects at the $\mathrm{ADJ}$ and subsequent regions in first-pass reading times, suggesting they occur rapidly and incrementally. The effects at the VP2 and NP3 regions echoed

\footnotetext{
7 This was true only for one contrast (first-pass reading times for the VP2 in sentences expressing similarity), and the $\mathrm{R}$ code used was: lmer (firstpass $\sim$ distance $*$ similarity $+(1 \mid$ participant $)+(0+$ distance $*$ similarity | participant $)+(1 \mid$ item $)+(0+$ distance $*$ similarity $\mid$ item $)$, data $)$
}

the reading-time pattern at the ADJ, suggesting that spatial information can have an extended effect during sentence interpretation. The absence of reliable effects of spatial distance before the adjective (at NP2) suggests that spatial information can modulate semantic similarity in a sentence context as soon as it is explicitly mentioned (at the ADJ), but perhaps not if it is implied by and-coordinated noun phrases (e.g., 'peace and war...'). ${ }^{8}$ Results from Experiment 1 are to the best of our knowledge the first evidence that visually-depicted spatial distance can affect incremental sentence interpretation (of similarity between two abstract nouns).

Rapid and incremental spatial distance effects could occur when card distance is integrated with noun phrase similarity incrementally, during sentence comprehension. Indeed, existing evidence has shown that semantic information from adjectives can be rapidly integrated with simultaneously presented non-linguistic visual information (e.g., Sedivy et al., 1999). However, it is also possible that the words displayed on the cards in Experiment 1 enabled pre-sentence integration of word meaning and card distance, since the two abstract nouns on the cards implied either semantic similarity or dissimilarity; perhaps this pre-sentence integration was responsible for the rapid spatial distance effects observed during sentence comprehension. Experiment 2 addressed this question.

\section{Experiment 2}

In our second experiment, we detached the nouns from the spatial information conveyed by the visual context. If the rapid and incremental effects of spatial distance need pre-sentence integration of spatial distance with word meaning, then we should observe no, or delayed, spatial distance effects when the nouns are presented temporally separated from the card context. Alternatively, if pre-sentence integration is not essential, then we should see rapid and incremental spatial distance effects emerge even when the words are presented temporally separated from the cards and the sentence trials.

To disentangle these two possibilities, we divided the experiment into six blocks of trials. Before each block, participants read and learnt a list of written noun pairs (among them all critical pairs of nouns of that block and an equal number of filler word pairs). In contrast with Experiment 1, the cards preceding each sentence remained blank. Consequently, participants saw the same noun pairs as in Experiment 1 but temporally detached from the cards

\footnotetext{
${ }^{8}$ It is possible that the pre-sentence presentation of written nouns (which then re-appeared as NP1 and NP2 in the sentence) induced shallow semantic processing of the NP2. In fact, positive skew values for first-pass reading times at NP2 indicate short inspection times (skew after logtransform $=.678, S E=.077)$. Repetition of words can speed up both word recognition and categorization (see Jacoby, 1983). This could be especially true for the NP2, since NP1 could have served as a cue of the previously seen word-pair. Such a reading strategy could have obscured potential spatial distance effects at the NP2 region on the assumption that deep semantic processing is pre-requisite for spatial distance effects on semantic interpretation.
} 
Table 2

Mean reading times in milliseconds and standard errors of the mean (by condition, region and measure) in Experiment 1.

\begin{tabular}{|c|c|c|c|c|c|c|c|}
\hline \multirow[t]{2}{*}{ Region } & \multirow[t]{2}{*}{ Condition } & \multicolumn{2}{|c|}{ First-pass } & \multicolumn{2}{|c|}{ Regression path } & \multicolumn{2}{|c|}{ Total time } \\
\hline & & Mean & $S E$ & Mean & $S E$ & Mean & $S E$ \\
\hline \multirow[t]{4}{*}{ NP2 } & Far-Dissimilar & 174.23 & 3.5 & 220.48 & 8.3 & 436.54 & 23.2 \\
\hline & Close-Dissimilar & 187.59 & 5.4 & 236.75 & 10.1 & 444.63 & 23.2 \\
\hline & Far-Similar & 180.49 & 4.3 & 222.54 & 9.0 & 442.58 & 24.8 \\
\hline & Close-Similar & 181.29 & 4.7 & 233.50 & 9.6 & 402.87 & 19.4 \\
\hline \multirow[t]{4}{*}{$\mathrm{ADJ}$} & Far-Dissimilar & 328.32 & 7.7 & 408.58 & 12.5 & 416.30 & 10.9 \\
\hline & Close-Dissimilar & 337.73 & 9.1 & 420.35 & 13.5 & 429.66 & 13.4 \\
\hline & Far-Similar & 311.79 & 8.0 & 377.34 & 12.5 & 354.49 & 8.7 \\
\hline & Close-Similar & 293.71 & 7.1 & 368.69 & 12.2 & 345.08 & 9.4 \\
\hline \multirow[t]{4}{*}{ VP2 } & Far-Dissimilar & 211.14 & 4.8 & 296.34 & 13.8 & 238.49 & 6.6 \\
\hline & Close-Dissimilar & 239.54 & 7.1 & 307.95 & 12.7 & 289.99 & 14.0 \\
\hline & Far-Similar & 218.60 & 5.7 & 312.94 & 14.1 & 253.19 & 8.8 \\
\hline & Close-Similar & 212.28 & 5.6 & 340.24 & 16.8 & 250.95 & 8.0 \\
\hline \multirow[t]{4}{*}{ NP3 } & Far-Dissimilar & 333.13 & 14.1 & 973.70 & 59.7 & 404.82 & 17.3 \\
\hline & Close-Dissimilar & 353.14 & 12.1 & 1006.58 & 61.3 & 418.43 & 15.3 \\
\hline & Far-Similar & 340.58 & 16.2 & 964.22 & 57.9 & 394.51 & 18.9 \\
\hline & Close-Similar & 318.26 & 11.1 & 849.97 & 45.4 & 367.87 & 13.4 \\
\hline
\end{tabular}

and the sentences. Therefore, participants could neither predict the semantic relationships between words of a given sentence nor integrate the card distance with these semantic relations prior to sentence reading.

\subsection{Method}

\subsubsection{Participants}

Thirty-two further native speaker of German with normal or corrected-to-normal vision (mean age: 23.19; range 19-29) participated in the experiment for a monetary compensation of 6 Euro. None of them had been exposed to a second language before age 6 . All participants gave informed consent.

\subsubsection{Materials and design}

The sentences and the experimental design were identical to Experiment 1 with the only difference that cards on all of the critical trials remained blank. The experiment-wide ratio of cards-with-words to blank cards was kept constant by including written words on the cards of 72 filler trials. Moreover, while in Experiment 1 blank cards were presented for $500 \mathrm{~ms}$ and cards-with-words for $4000 \mathrm{~ms}$ after they turned around, in Experiment 2 cards both blank fronts and written words were presented for $3000 \mathrm{~ms}$ to eliminate presentation-related differences between these trials.

\subsubsection{Procedure and analysis}

Both analysis and procedure were identical to Experiment 1 with the following exception: Experiment 2 was divided in six blocks of 24 trials each. Participants learnt a list of 16 word pairs ( 8 critical and 8 filler pairs) before each block of trials. These pairs appeared in 16 of the 24 sentences in a block. Participants were given the list of word-pairs to study. After they declared knowing the word pairs, a memory test ensured a minimum of $75 \%$ of accuracy for each list. The same procedure was repeated on each block.

\subsection{Results}

Accuracy on the test lists was high for all participants ( mean $=96.8 \%$, range $=95-100 \%$ ) suggesting they were able to memorize the noun pairs. Table 4 shows mean reading times in milliseconds per condition, for all measures and regions analyzed. Table 5 presents the results from the linear mixed-effect regression analyses.

The analyses confirmed a main effect of similarity in regression path duration at the NP2 region (all other $t s<|2|)$. At the ADJ region a main effect of similarity and a marginally significant interaction effect between spatial distance and semantic similarity were found in regression path duration $(t=-1.89)$. Further, a reliable interaction effect was seen in total reading times $(t=-2.43)$. In these two measures, reading times were shorter for sentences expressing similarity when the sentence were preceded by cards close to each other compared to far apart; by contrast, the ADJ region of sentences that expressed dissimilarity showed shorter reading times when the preceding cards were far apart compared to close together. For the NP3 region, the main effect of similarity was reliable in regression path duration and total reading times (all other ts $<|2|)$.

Pairwise comparisons for regression path duration and total reading time at the $\mathrm{ADJ}$ region showed no reliable effect of spatial distance for sentences that expressed similarity $(t s<|2|)$ but a marginal and a reliable effect of spatial distance for sentences that expressed dissimilarity were observed, respectively (regression path duration, $t=-1.97$; total reading times $t=-2.83$ ).

\subsection{Discussion}

In our first experiment we observed that spatial distance modulated semantic interpretation, and it did so rapidly and incrementally. However, it was not clear whether these effects depended on spatial-semantic integration prior to sentence reading. We separated the semantic 


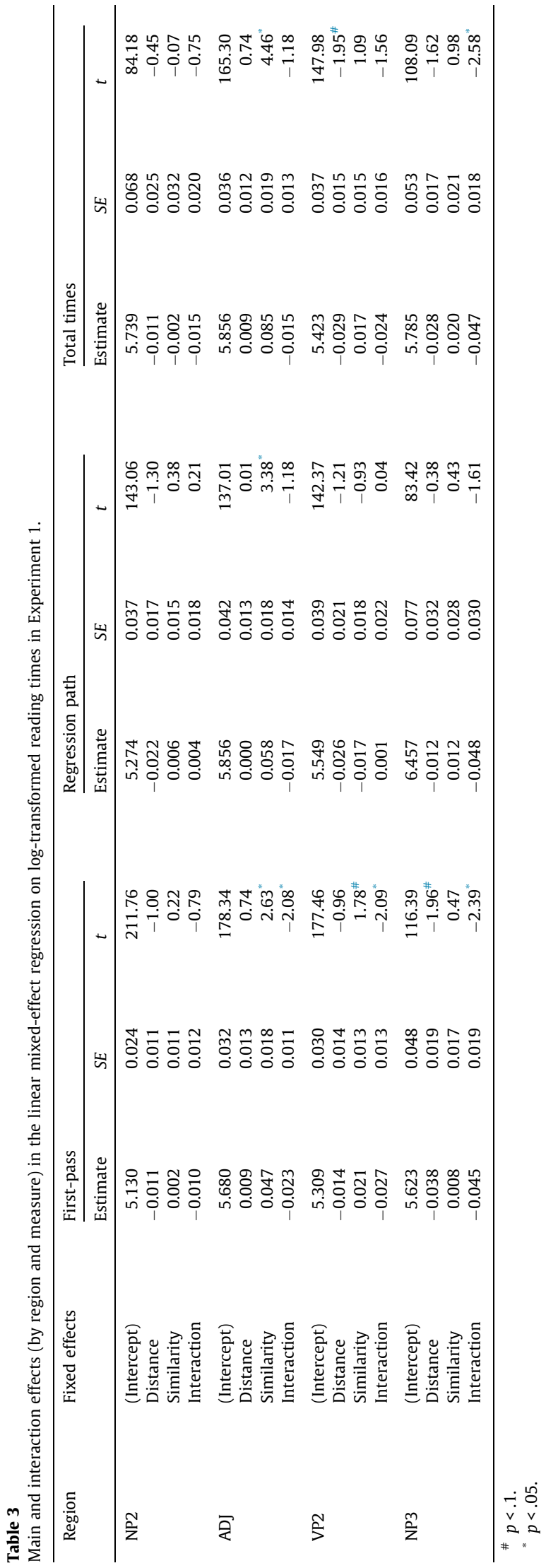

information provided by the words from spatial information in the visual context, and replicated spatial distance effects in Experiment 2. As in Experiment 1, spatial distance effects did not emerge at NP2 but only later, once semantic similarity was explicitly mentioned (the ADJ region). This results show that spatial distance can modulate the interpretation of semantic relations between abstract concepts when it is explicitly mentioned and even when spatial distance has to be integrated with semantic similarity on the fly.

While spatial distance effects emerged consistently at the ADJ region, they appeared in an earlier measure (first-pass reading times) in Experiment 1 compared to Experiment 2 (marginal in regression path duration, and significant in total reading times). The delay could have resulted from the immediate integration of card distance with the semantic relations during sentence processing. Alternatively (or in addition), the first noun phrase of the sentence may have cued retrieval of previously seen or learnt semantic relations. This retrieval process and the integration of studied word pairs with the sentence content and spatial distance information could have delayed the spatial distance effects.

\section{Experiment 3}

In our third experiment, the cards for all trials were blank, and participants saw no word pairs before sentence reading. Thus, upon encountering the cards or even the first noun phrase in a critical sentence, participants did not have any information about the semantic relations expressed by the sentence. If retrieval processes delayed spatial distance effects in Experiment 2 but otherwise the integration of semantic relations and spatial distance during comprehension can occur rapidly, then we should observe effects of spatial distance in first-pass times in Experiment 3.

Moreover, Experiment 3 examined spatial distance effects on semantic interpretation in the absence of any links other than temporal contiguity (the cards appeared immediately before the sentence). Card distance was irrelevant to the sentence comprehension task in all three experiments, but in the first two experiments the visual context was somehow related to the sentence via words on the cards. Experiment 3 thus provides a strong test of whether spatial distance alone can modulate the incremental semantic interpretation of similarity relations.

\subsection{Method}

\subsubsection{Participants}

Another thirty-two native speakers of German with normal or corrected-to-normal vision (mean age: 24,37; range 20-31) participated in the experiment for a monetary compensation of 6 Euro. None of them had been exposed to a second language before age 6 . All participants gave informed consent.

\subsubsection{Material, design, procedure and data analysis}

Critical sentence stimuli, design, procedure and analysis were the same as in Experiment 1. However, cards on all 


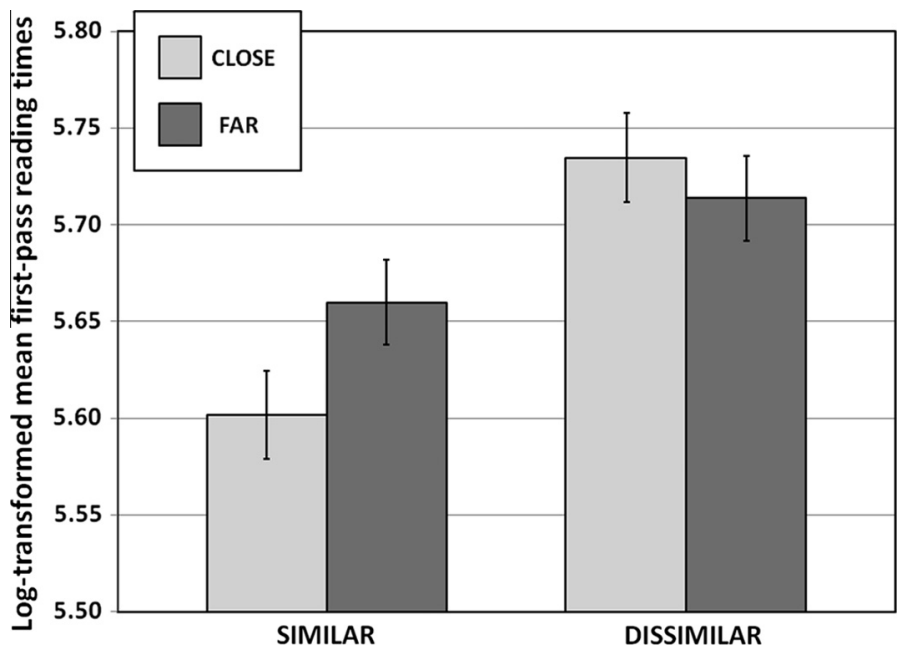

Fig. 3. Log-transformed mean first-pass time (with error bars plotting the standard error of the mean) for the ADJ region as a function of sentence type and spatial distance between cards-with-words in Experiment 1.

trials were blank in Experiment 3. As in Experiment 2, cards turned around after $3000 \mathrm{~ms}$ and presented the front side for another $3000 \mathrm{~ms}$.

\subsection{Results}

Table 6 shows mean reading times in milliseconds per condition, for all measures and analyzed regions. Table 7 shows the results from the linear mixed-effect regression analyses. At the NP2 we found a marginally significant main effect of similarity in first-pass time $(t=1.94)$ as well as a significant interaction of spatial distance and semantic similarity $(t=-2.15)$. First-pass time for sentences that expressed similarity were shorter when cards were close together (vs. far apart), while first-pass time for sentences that expressed dissimilarity were shorter when preceded by cards far apart (vs. close together). No other effects were observed for this region. At the ADJ region we observed a statistically significant similarity main effect in regression path duration (other $t s<|2|$ ). Analysis of the VP2 showed a reliable interaction between spatial distance and semantic similarity $(t=-2.07$; all other $t s<|2|)$. Finally, at the NP3 region we found reliable main effects for both spatial distance and semantic similarity $(t s>|2|)$ in regression path duration (other $t s<|2|$ ).

Qualitatively, the gaze pattern underlying the interaction at NP2 and VP2 resembled that at the ADJ region in Experiments 1 and 2. Pairwise comparisons for first-pass time at NP2 revealed reliable effects of spatial distance for sentences that expressed dissimilarity $(t=-2.03$; other $t \mathrm{~s}<|2|)$.

\subsection{Discussion}

The analyses in Experiment 3 revealed a rapid (firstpass) and incremental (at the NP2 region) interaction of spatial distance and semantic similarity. These results

Table 4

Mean reading times in milliseconds and standard errors of the mean (by condition, region and measure) in Experiment 2.

\begin{tabular}{|c|c|c|c|c|c|c|c|}
\hline \multirow[t]{2}{*}{ Region } & \multirow[t]{2}{*}{ Condition } & \multicolumn{2}{|c|}{ First-pass } & \multicolumn{2}{|c|}{ Regression path } & \multicolumn{2}{|c|}{ Total time } \\
\hline & & Mean & $S E$ & Mean & $S E$ & Mean & $S E$ \\
\hline \multirow[t]{4}{*}{ NP2 } & Far-Dissimilar & 229.46 & 5.18 & 298.05 & 11.34 & 465.67 & 19.51 \\
\hline & Close-Dissimilar & 227.09 & 5.09 & 261.97 & 7.08 & 453.04 & 20.22 \\
\hline & Far-Similar & 224.87 & 5.06 & 242.40 & 5.91 & 498.36 & 21.51 \\
\hline & Close-Similar & 225.07 & 5.08 & 249.76 & 6.54 & 423.43 & 15.52 \\
\hline \multirow[t]{4}{*}{ ADJ } & Far-Dissimilar & 330.47 & 7.48 & 402.16 & 10.98 & 389.54 & 10.02 \\
\hline & Close-Dissimilar & 334.47 & 8.26 & 437.23 & 13.26 & 433.52 & 11.79 \\
\hline & Far-Similar & 350.36 & 9.59 & 397.96 & 11.66 & 405.27 & 12.17 \\
\hline & Close-Similar & 330.15 & 7.96 & 379.67 & 10.65 & 389.19 & 10.90 \\
\hline \multirow[t]{4}{*}{ VP2 } & Far-Dissimilar & 227.96 & 6.23 & 329.58 & 14.77 & 292.55 & 11.43 \\
\hline & Close-Dissimilar & 227.15 & 5.53 & 300.67 & 11.15 & 283.03 & 9.56 \\
\hline & Far-Similar & 240.62 & 6.73 & 289.34 & 9.15 & 311.67 & 12.70 \\
\hline & Close-Similar & 227.65 & 5.56 & 297.63 & 11.08 & 318.00 & 13.75 \\
\hline \multirow[t]{4}{*}{ NP3 } & Far-Dissimilar & 354.40 & 12.29 & 951.21 & 48.98 & 426.59 & 16.44 \\
\hline & Close-Dissimilar & 357.01 & 12.67 & 1028.25 & 57.45 & 432.37 & 16.24 \\
\hline & Far-Similar & 380.99 & 14.66 & 1170.14 & 57.51 & 464.08 & 16.83 \\
\hline & Close-Similar & 379.55 & 14.75 & 1152.59 & 64.42 & 466.12 & 17.79 \\
\hline
\end{tabular}




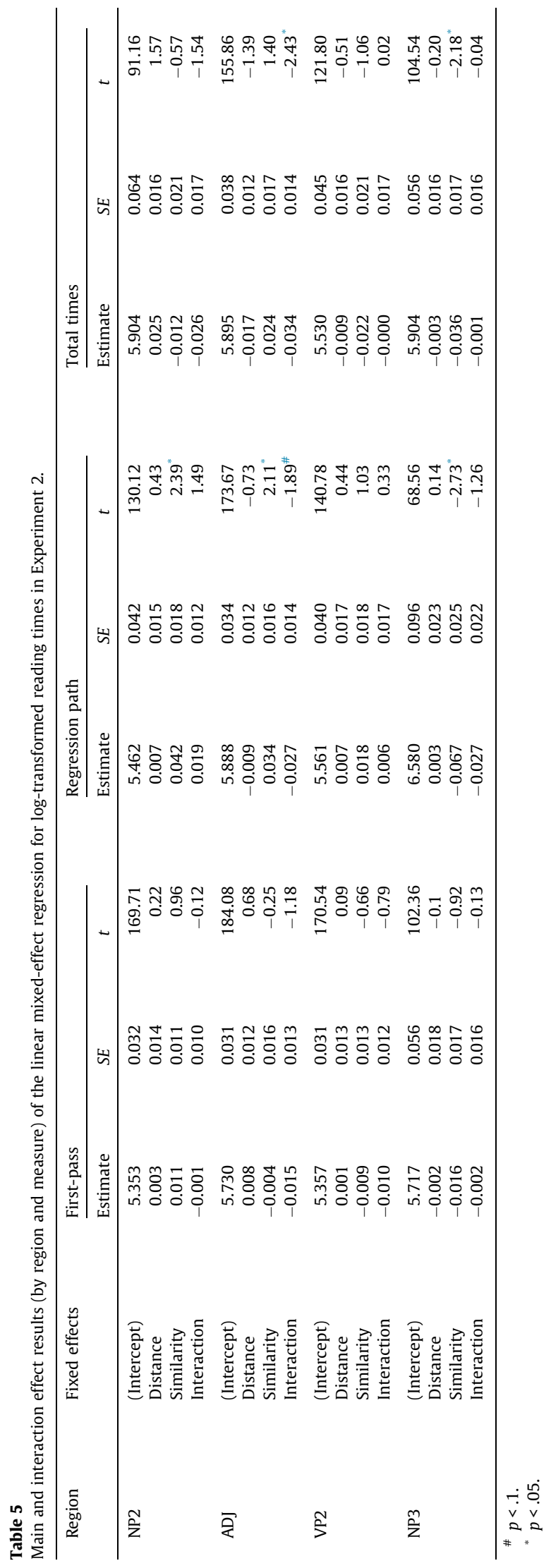

show that even in the absence of any overt relation between a visual context and subsequent sentence content, non-linguistic spatial information can affect the semantic interpretation of conjoined abstract nouns.

We observed spatial distance effects at the NP2 region in Experiment 3 and therefore earlier in the sentence compared to the first two experiments. Potentially the absence of earlier interaction effects (at NP2) in the first two experiments resulted from the repetition of the words. Seeing the two abstract words before the sentence might have prompted participants to process the and-coordination more superficially during sentence reading, such that its meaning was not immediately integrated with spatial distance. On the other hand, the earlier effects in Experiment 3 (at NP2) than Experiment 2 (in regression path times at the $\mathrm{ADJ}$ region) suggest that the relative delay we observed in Experiment 2 was unlikely caused by immediate integration of semantic similarity and spatial distance and more likely resulted from the cued retrieval of previously-learnt semantic relations.

One issue remains: It is unclear why effects of spatial distance were absent at the ADJ region in Experiment 3, while they were present in Experiments 1 and 2. One possibility is that integration of spatial information and implicit semantic similarity at the NP2 drew attention to spatial distance in a way that changed the effects of spatial distance at the downstream ADJ region. Tentative evidence for the view that spatial distance and semantic similarity processing interacted in a different way at the ADJ region in Experiment 3 (compared to the first two experiments) comes from the different reading-time pattern at that region (first-pass reading times for similarity-conveying sentences were longer when cards were close together than far apart). Overall, our results are the first experimental data showing rapid and incremental effects of spatial distance on the semantic interpretation of abstract language.

\section{General discussion}

Three eye-tracking reading experiments assessed whether spatial distance between objects could rapidly and incrementally facilitate the semantic interpretation of abstract sentences when distance information was not mediated by referential or lexical-semantic links. We manipulated the semantic content of written sentences (similarity vs. dissimilarity between two abstract nouns) and spatial distance in the visual context (playing cards moving closer together or farther apart). Spatial distance and semantic similarity were never referentially or lexico-semantically linked, ${ }^{9}$ and between experiments, we varied their relatedness. In our first experiment, cards showed two abstract nouns that re-appeared in the ensuing sentence on critical trials. In our second experiment, cards were blank on critical tri-

\footnotetext{
${ }^{9}$ It might be argued that the repetition of words (on the cards and in the sentence) counts as a 'referential' link. Note, however, that merely relating individual words on the cards to words in the sentence could not have caused the observed spatial distance effects. Rather, for these effects to emerge, participants must process the distance between two objects, the semantic similarity between two abstract nouns, and then integrate these two representations.
} 
Table 6

Mean reading times in milliseconds and standard errors of the mean (by condition, region and measure) in Experiment 3.

\begin{tabular}{|c|c|c|c|c|c|c|c|}
\hline \multirow[t]{2}{*}{ Region } & \multirow[t]{2}{*}{ Condition } & \multicolumn{2}{|c|}{ First-pass } & \multicolumn{2}{|c|}{ Regression path } & \multicolumn{2}{|c|}{ Total time } \\
\hline & & Mean & $S E$ & Mean & $S E$ & Mean & $S E$ \\
\hline \multirow[t]{4}{*}{ NP2 } & Far-Dissimilar & 313.71 & 9.57 & 434.60 & 19.91 & 614.25 & 23.43 \\
\hline & Close-Dissimilar & 354.92 & 11.78 & 411.96 & 14.49 & 614.59 & 22.63 \\
\hline & Far-Similar & 300.14 & 8.42 & 415.25 & 19.59 & 608.56 & 27.23 \\
\hline & Close-Similar & 290.28 & 8.63 & 382.56 & 19.37 & 635.67 & 29.73 \\
\hline \multirow[t]{4}{*}{ ADJ } & Far-Dissimilar & 363.66 & 8.99 & 436.77 & 12.19 & 427.85 & 11.24 \\
\hline & Close-Dissimilar & 350.02 & 9.72 & 428.57 & 13.02 & 442.61 & 14.23 \\
\hline & Far-Similar & 334.79 & 9.08 & 389.74 & 11.66 & 409.38 & 11.91 \\
\hline & Close-Similar & 343.45 & 9.96 & 405.83 & 13.65 & 432.26 & 14.87 \\
\hline \multirow[t]{4}{*}{ VP2 } & Far-Dissimilar & 229.47 & 5.86 & 297.56 & 10.44 & 269.98 & 8.42 \\
\hline & Close-Dissimilar & 249.01 & 7.15 & 334.17 & 13.59 & 308.65 & 11.09 \\
\hline & Far-Similar & 239.95 & 6.16 & 336.13 & 13.38 & 299.32 & 10.68 \\
\hline & Close-Similar & 236.70 & 6.80 & 337.50 & 14.88 & 331.05 & 16.33 \\
\hline \multirow[t]{4}{*}{ NP3 } & Far-Dissimilar & 393.35 & 15.44 & 1095.71 & 61.03 & 475.64 & 19.26 \\
\hline & Close-Dissimilar & 419.48 & 17.99 & 1131.12 & 57.81 & 497.81 & 19.62 \\
\hline & Far-Similar & 402.99 & 15.75 & 1198.33 & 63.58 & 526.88 & 20.49 \\
\hline & Close-Similar & 411.50 & 18.62 & 1283.04 & 70.90 & 514.92 & 20.56 \\
\hline
\end{tabular}

als but participants learnt the pairing of abstract nouns in blocks, prior to reading the sentences, and on most filler trials cards showed words that re-appeared in the subsequent sentence. In our third experiment, cards in the visual context were always blank, thus eliminating any overt relation other than temporal contiguity between card distance and the (semantic similarity of the) sentential nouns.

In Experiment 1, we observed faster reading times when sentences about similarity were preceded by cards-withwords close to each other (vs. far apart), and when sentences that expressed dissimilarity were preceded by cards-withwords far apart (vs. close together). This reading time pattern was reliable at the ADJ, the VP2 and the NP3 regions in first-pass reading times. In Experiment 2, the same reading time pattern emerged at the ADJ, however, in later measures (total times). Together the first two experiments showed that when visual context was related to a subsequent sentence (through words on cards for critical items in Experiment 1; through words on cards for filler items in Experiment 2), then spatial distance facilitated the interpretation of semantic similarity between two abstract nouns.

In Experiment 3 we had removed any overt relation between the cards in the visual context and the subsequent sentence. Nevertheless, we replicated rapid and incremental spatial distance effects. When two blank cards were presented either close together or farther apart in the visual context, spatial information rapidly influenced incremental semantic interpretation of sentences about similarity or dissimilarity between two abstract nouns. First-pass times at NP2 and VP2 for sentences expressing semantic similarity were shorter when preceded by cards close to each other compared to far apart and they were longer for sentences expressing dissimilarity when cards were far apart compared to close to each other.

\subsection{Visual-context representation and abstract sentence processing: beyond lexical priming}

The results from these three experiments revealed that information from the non-linguistic visual context can rapidly and incrementally modulate the semantic interpretation of abstract sentences and that this can happen even in the absence of referential or lexical-semantic links. One potential mechanism underlying this effect could be lexical priming. A recent study, for instance, showed rapid effects of abstract language on visual attention during spoken language comprehension. When participants heard an abstract word (e.g., 'smell'), they inspected an object (e.g., a nose) associated with that word more often than nonassociated objects (Duñabeitia, Avilés, Afonso, Scheepers, \& Carreiras, 2009). Previous studies have demonstrated that concrete language can guide visual attention to unmentioned objects, for instance, through subtle associations between a color adjective and the color of an object (e.g., Dahan \& Tanenhaus, 2005; Huettig \& Altmann, 2011; Huettig \& McQueen, 2007). These effects are triggered by specific lexical input; they seem insensitive to linguistic contextual appropriateness (see Huettig \& Altmann, 2007); and they can be accommodated by a lexical-associative account. In this regard they are indeed different from our findings.

The new insight from our results is that a visuallyderived representation (i.e., of spatial distance between playing cards) selectively modulates semantic similarity between two abstract nouns during incremental semantic interpretation. To accommodate these results, lexicalsemantic priming (e.g., spreading activation from a word to a concept) is not sufficient. Spreading-activation has been proposed to explain semantic priming in a singleword context (e.g., Anderson \& Pirolli, 1984; Collins \& Loftus, 1975; Hutchison, 2003), and also in the context of real-time sentence comprehension (e.g., Carroll \& Slowiaczek, 1986; Morris, 1994).

At first blush, the effect in our studies might seem to arise from simple priming of individual lexical items (e.g., when participants encounter the word 'similar', they process it faster if they had previously activated the concept of spatial proximity rather than distance). Critically, the time course of the reported effects in the context of our sentence stimuli permits us to exclude a lexical-semantic 


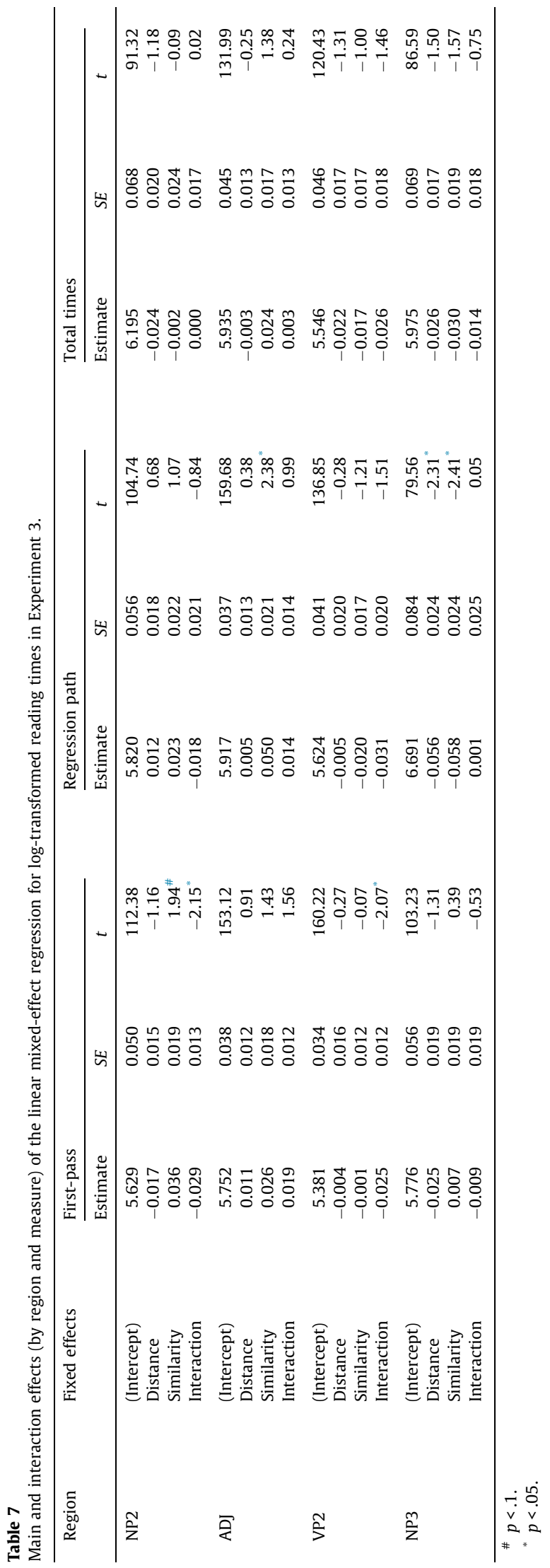

priming account. Results from Experiment 3 show that spatial distance effects appeared at the earliest possible point in time (i.e., in first-pass times at the NP2 region), where semantic similarity (or dissimilarity) was implied by the combination of the first two noun phrases. This effect cannot be explained through lexical-semantic priming alone, since similarity was not conveyed by just one word (e.g., 'battle'). Instead, it arises from the interpretation of the and-coordination of two abstract synonyms ('Battle and war') or antonyms ('Peace and war'). The observed facilitation or priming therefore required compositional processing. In Experiment 1 similar effects occurred only in subsequent regions (ADJ, VP2, and NP3). Word repetition might have discouraged deep semantic processing of the first two sentential nouns in Experiment 1 (see Jacoby, 1983), such that semantic similarity and spatial distance representations were not integrated at the NP2. Nevertheless, the effects extended from the ADJ region to the next two sentence regions (VP2, NP3). Again these extended effects are unlikely best accommodated by lexical semantic priming alone.

\subsection{Implications for processing accounts of language in context}

In sum, the results from these three experiments are the first evidence for rapid effects of non-referential spatial information on the incremental comprehension of abstract language. One interesting question concerns how we could accommodate these new results in existing accounts of situated language processing. Such accounts predict a close temporal coordination between when words in the utterance mediate relevant aspects of visual context and when visual context affects language comprehension (e.g., Knoeferle \& Crocker, 2006, 2007; Tanenhaus, Magnuson, Dahan, \& Chambers, 2000). In particular, the Coordinated Interplay Account (Knoeferle \& Crocker, 2007) assumes that the partial sentence interpretation can rapidly guide (visual) attention to relevant scene information or representations thereof in working memory. Linguistic and visually-derived representations are then co-indexed and in this process visual context representations can influence on-going language comprehension. Co-indexing occurs via reference between nouns and concrete objects, or verbs and concrete actions in the Coordinated Interplay. With respect to abstract language and non-referential contexts, two interesting issues arise: First, how does language guide attention to relevant visual-context representations (of spatial distance)? And second, how are these representations of the visual context co-indexed with the linguistic representations?

Consider the first of these two issues: In our experiments, participants were instructed to attentively inspect the visual context and keep it in memory. At the beginning of a sentence, their working memory presumably included representations of spatial distance, card color, and position, amongst others. Next, participants encountered the sentence-initial noun phrase coordination. The interpretation of these noun phrases as semantically similar or dissimilar could direct their attention to the spatial-distance representations, and these would then be integrated with the unfolding interpretation (the representations of the noun 
phrases and of the adjectival term). This account (that interpretation of the noun phrases singles out pre-activated distance representations) fits well with the time course of spatial distance effects in Experiment 3. When the cards were entirely unrelated to the sentence (Experiment 3 ), the two noun phrases were processed in-depth and compositional semantic interpretation of these noun phrases singled out relevant visual context representations, eliciting spatial distance effects on semantic interpretation. By contrast, when participants either encountered the noun pairs immediately before the sentence (Experiment 1) or learnt them minutes before sentence reading (Experiment 2), spatial distance effects emerged at the ADJ region. We think that in this case participants did not process in-depth the already-seen noun phrases and that the adjective was then the first word to guide attention to relevant visual context representations.

An alternative possibility is that the pre-activated spatial distance representations activate semantic similarity even before participants read the sentence. However, if this were the case for the present experiments, then we should have seen more immediate effects of spatial distance (consistently in first-pass times). In Experiment 2 in particular, when the cards on critical trials were blank and participants learnt the noun pairs minutes before sentence reading, we should have seen more early top-down effects of the visual context in first-pass times. This was not the case, suggesting that instead semantic interpretation of the sentence guided participants' attention to relevant aspects of the visual context representations.

With respect to the second issue (how spatial distance representations are co-indexed with semantic representations), the present findings permit us to refine the co-indexing mechanism in the Coordinated Interplay Account. Co-indexing of card distance and semantic similarity could happen in several ways. As a first possibility, the two noun phrases could be directly co-indexed with the cards. This appears plausible when the cards present the first two sentential nouns as was the case in Experiment 1. Alternatively, the spatial representation of object distance is co-indexed with the abstract semantic representation of similarity, implied by the two NPs and conveyed by the ADJ. In the latter case, co-indexing would not occur between the two cards and the corresponding and-coordinated NPs but rather between the representations activated by the cards in the visual context and those activated by the unfolding sentence interpretation.

A refined co-indexing mechanism that also allows conceptual (non-referential) mapping between language and visual context could accommodate effects of spatial distance on sentence interpretation even in the absence of and-coordination. This idea fits with the emergence of spatial distance effects at NP2 (Experiment 3) and also at sentence regions that do not imply semantic similarity (e.g., VP2 and NP3, 'said the professor' in Experiment 1). At NP2, semantic similarity is implied following the interpretation of the two noun phrases, suggesting that direct reference from a single lexical item to aspects of the visual context is not necessary for co-indexing. At the later sentence regions (VP2 and NP3), semantic similarity is not conveyed; however, the initial sentence is a relative clause to the sentence-final region 'said the professor'. Its content thus depends from the super-ordinate clause and may well be re-activated for that reason during the super-ordinate clause, eliciting the extended spatial distance effects on semantic similarity or dissimilarity that we observed.

The idea of a non-referential co-indexing mechanism could further be tested by changing the structure of the sentences (e.g., NP-V-NP instead of NP-and-NP). If coindexing of the card representations to the co-ordinated nouns is essential for the rapid spatial-distance effects that we observed, then these effects should be eliminated when we break up the correspondence of jointly moving cards and corresponding coordinated noun phrases by changing the sentence structure to NP-V-NP. By contrast, if this correspondence is non-essential, then we should replicate rapid spatial distance effects on semantic interpretation even when the cards remain coordinated (through their joint movement) but the noun phrases are not. In fact, recent results from our laboratory suggest that spatial distance between cards affects real time semantic interpretation in other semantic domains and even in the absence of and-coordinated noun phrases (Guerra \& Knoeferle, 2014).

Together the results from these three experiments are the first evidence for rapid effects of non-referential spatial information on the incremental comprehension of abstract language. While these effects permit us to refine our insight into the time course of visually situated language comprehension when language is abstract and non-referential, one open issue is whether they implicate metaphorical mapping. A metaphorical mapping mechanism could potentially contribute towards forging the links from perceptual and motor experience to abstract conceptualization during conceptual learning and language acquisition (see Grady \& Johnson, 1997; Johnson, 1999). Yet, the present study cannot distinguish whether we re-enact the metaphorical mapping between spatial distance and semantic similarity in real time every time we read about similarity, or whether we exploit instead pre-computed associations that originate from metaphorical mapping. It is possible that such associations link spatial distance and semantic similarity. However, we have argued that our results cannot be explained in terms of lexical-semantic associations alone. Similarly we acknowledge that, in a more natural context, a reader may rarely see two unrelated objects moving apart or close together just before reading a sentence about similarity. The main insight from these results, with regard to written sentence comprehension is that they show how language interpretation can be modulated by apparently unrelated visual information. We explored the relation between spatial distance and similarity, but further research could reveal the extent of non-referential visual context effects on reading.

We have further described how interpretation of the unfolding utterance can single out relevant spatial-distance representations that can then be co-indexed and inform the interpretation. Co-indexing thus implicates a one-to-one mapping (e.g., from a noun to an object, or from a verb to an action), but can also serve to relate abstract concepts of semantic similarity (that come about through compositional semantic interpretation) to representations of spatial information. The Coordinated Interplay Account enriched with these assumptions (a mapping from abstract nouns to non-linguistic representations of spatial distance; 
a co-indexing mechanism that is not just referential) can accommodate the real-time effects that we observed.

\section{Conclusion}

The results presented in this paper extend previous findings of spatial distance effects on similarity ratings (Casasanto, 2008) and response times (Boot \& Pecher, 2010) to incremental language processing. They also provide strong evidence for the role of spatial information in abstract language comprehension in agreement with theories of grounded cognition (see Lakoff \& Johnson, 1999). These findings are further compatible with the view that relations between non-linguistic and linguistic stimuli, which might have emerged during language acquisition through metaphorical mapping (see Grady \& Johnson, 1997; Johnson, 1999), contribute towards incremental language processing. Rapid and incremental non-linguistic effects on abstract language comprehension were observed beyond referential or lexicalsemantic associative links. Finally, our findings support the view that visually-derived perceptual information (i.e. spatial distance between objects) contributes to the construction of meaning during real-time language comprehension.

\section{Acknowledgements}

This research was funded by the Cognitive Interaction Technology Excellence Cluster (German research foundation, DFG), the SFB 673 "Alignment in Communication", and by a PhD scholarship awarded to EG by the Ministry of Education, Government of Chile. The authors want to thank Maria Nella Carminati for her valuable comments on an earlier version of this paper, and the members of the Language and Cognition Lab (CITEC, University of Bielefeld) for insightful discussion at group meetings. We also thank Albert Kim as well as two anonymous reviewers for their helpful comments.

\section{Appendix A}

Critical sentences: 48 experimental sentences, each with two versions; either expressing dissimilarity (a) or similarity (b) between two abstract nouns.

1. (a) Souveränität und Unsicherheit sind geradezu umgekehrt, so argumentierte die Denkerin.

(b) Verlegenheit und Unsicherheit sind ziemlich einheitlich, so argumentierte die Denkerin.

2. (a) Munterkeit und Mattigkeit sind geradezu umgekehrt, so begründete die Logopädin. (b) Ermüdung und Mattigkeit sind ziemlich einheitlich, so begründete die Logopädin.

3. (a) Hochverrat und Loyalität sind geradezu umgekehrt, das behauptete die Fußballspielerin. (b) Ergebenheit und Loyalität sind ziemlich einheitlich, das behauptete die Fußballspielerin.

4. (a) Fortuna und Unglück sind sicher ungleich, so ersann der Clown.

(b) Unheil und Unglück sind gewiss verwandt, so ersann der Clown.
5. (a) Ignoranz und Vorgefühl sind bestimmt verschieden, so träumte das Medium.

(b) Vorahnung und Vorgefühl sind freilich entsprechend, so träumte das Medium.

6. (a) Frieden und Krieg sind bestimmt verschieden, das verriet der Anthropologe.

(b) Kampf und Krieg sind freilich entsprechend, das verriet der Anthropologe.

7. (a) Werktag und Ruhepause sind sicher ungleich, das beschwur der Arbeiter.

(b) Atempause und Ruhepause sind gewiss verwandt, das beschwur der Arbeiter.

8. (a) Ohnmacht und Können sind bestimmt verschieden, das verkündete der Artist.

(b) Talent und Können sind freilich entsprechend, das verkündete der Artist.

9. (a) Freudenruf und Wutanfall sind sicher ungleich, so bekundete der Boxer.

(b) Zornausbruch und Wutanfall sind gewiss verwandt, so bekundete der Boxer.

10. (a) Betrug und Benehmen sind eher andersartig, so verkündigte der Polizeibeamte.

(b) Anstand und Benehmen sind fast äquivalent, so verkündigte der Polizeibeamte.

11. (a) Dummheit und Weisheit sind bestimmt verschieden, das erklärte der Professor.

(b) Begabung und Weisheit sind freilich entsprechend, das erklärte der Professor.

12. (a) Lebensfreude und Traurigkeit sind geradezu umgekehrt, so tönte die Dichterin.

(b) Melancholie und Traurigkeit sind ziemlich einheitlich, so tönte die Dichterin.

13. (a) Frohsinn und Trübsinn sind geradezu umgekehrt, so empfahl die Frau.

(b) Schwermut und Trübsinn sind ziemlich einheitlich, so empfahl die Frau.

14. (a) Diebstahl und Bezahlung sind geradezu umgekehrt, so schrie die Gewerkschaftlerin.

(b) Vergütung und Bezahlung sind ziemlich einheitlich, so schrie die Gewerkschaftlerin.

15. (a) Verstimmung und Wohlbefinden sind eher andersartig, so ließ die Kinderärztin verlauten. (b) Zufriedenheit und Wohlbefinden sind fast äquivalent, so ließ die Kinderärztin verlauten.

16. (a) Infektion und Gesundung sind geradezu umgekehrt, so dachte die Krankenschwester. (b) Genesung und Gesundung sind ziemlich einheitlich, so dachte die Krankenschwester.

17. (a) Betrübnis und Euphorie sind eher andersartig, so antwortete die Lehrerin.

(b) Entzücken und Euphorie sind fast äquivalent, so antwortete die Lehrerin.

18. (a) Trennung und Heirat sind geradezu umgekehrt, so beurteilte die Organisatorin.

(b) Hochzeit und Heirat sind ziemlich einheitlich, so beurteilte die Organisatorin.

19. (a) Minorität und Majorität sind eher andersartig, das erkannte die Präsidentin. 
(b) Übermacht und Majorität sind fast äquivalent, das erkannte die Präsidentin.

20. (a) Unwohlsein und Wohlgefühl sind eher andersartig, so erwiderte die Psychologin.

(b) Wohlbehagen und Wohlgefühl sind fast äquivalent, so erwiderte die Psychologin.

21. (a) Bestrafung und Belohnung sind eher andersartig, das bestätigte die Richterin.

(b) Besoldung und Belohnung sind fast äquivalent, das bestätigte die Richterin.

22. (a) Kräftigkeit und Schwachheit sind eher andersartig, das beteuerte die Sportlehrerin. (b) Ermattung und Schwachheit sind fast äquivalent, das beteuerte die Sportlehrerin.

23. (a) Aufregung und Entspannung sind eher andersartig, das bekräftigte die Therapeutin. (b) Erholung und Entspannung sind fast äquivalent, das bekräftigte die Therapeutin.

24. (a) Feindschaft und Kameradschaft sind eher andersartig, das enthüllte die Beraterin.

(b) Partnerschaft und Kameradschaft sind fast äquivalent, das enthüllte die Beraterin.

25. (a) Zustimmung und Widerspruch sind bestimmt verschieden, so entschied der Lehrer.

(b) Opposition und Widerspruch sind freilich entsprechend, so entschied der Lehrer.

26. (a) Illusion und Gewissheit sind bestimmt verschieden, das erzählte der Wissenschaftler.

(b) Tatbestand und Gewissheit sind freilich entsprechend, das erzählte der Wissenschaftler.

27. (a) Leid und Glanz sind eher andersartig, das äußerte das Fotomodell.

(b) Ruhm und Glanz sind fast äquivalent, das äußerte das Fotomodell.

28. (a) Abneigung und Zuneigung sind sicher ungleich, so meinte der Großvater.

(b) Zuwendung und Zuneigung sind gewiss verwandt, so meinte der Großvater.

29. (a) Konflikt und Einigung sind bestimmt verschieden, das fand der Historiker.

(b) Eintracht und Einigung sind freilich entsprechend, das fand der Historiker.

30. (a) Rückzug und Offensive sind sicher ungleich, so brüllte der Infanterist.

(b) Feldzug und Offensive sind gewiss verwandt, so brüllte der Infanterist.

31. (a) Faktum und Märchen sind bestimmt verschieden, so las der Journalist.

(b) Fiktion und Märchen sind freilich entsprechend, so las der Journalist.

32. (a) Unbegabtheit und Kreativität sind geradezu umgekehrt, so korrigierte die Wahrsagerin.

(b) Genialität und Kreativität sind ziemlich einheitlich, so korrigierte die Wahrsagerin.

33. (a) Humor und Trauer sind eher andersartig, so deklarierte das Mädchen.

(b) Kummer und Trauer sind fast äquivalent, so deklarierte das Mädchen.

34. (a) Jammer und Pracht sind bestimmt verschieden, das glaubte der Mann.

(b) Luxus und Pracht sind freilich entsprechend, das glaubte der Mann.

35. (a) Gewinn und Verlust sind sicher ungleich, so zeterte der Politiker.

(b) Schaden und Verlust sind gewiss verwandt, so zeterte der Politiker.

36. (a) Hochgefühl und Höllenangst sind bestimmt verschieden, so rezitierte der Poet.

(b) Herzensangst und Höllenangst sind freilich entsprechend, so rezitierte der Poet.

37. (a) Friedsamkeit und Zwietracht sind geradezu umgekehrt, das rief die Priesterin.

(b) Streiterei und Zwietracht sind ziemlich einheitlich, das rief die Priesterin.

38. (a) Übereinkunft und Kampfhandlung sind bestimmt verschieden, das sagte der Soldat. (b) Konfrontation und Kampfhandlung sind freilich entsprechend, das sagte der Soldat.

39. (a) Dissonanz und Wohlklang sind sicher ungleich, das bejahte der Sänger.

(b) Wohllaut und Wohlklang sind gewiss verwandt, das bejahte der Sänger.

40. (a) Glück und Sorge sind sicher ungleich, das schrieb der Schauspieler.

(b) Angst und Sorge sind gewiss verwandt, das schrieb der Schauspieler.

41. (a) Fairness und Mogelei sind sicher ungleich, das weissagte der Schiedsrichter.

(b) Gaunerei und Mogelei sind gewiss verwandt, das weissagte der Schiedsrichter.

42. (a) Antipathie und Liebelei sind eher andersartig, das stellte der Schreiber fest.

(b) Romanze und Liebelei sind fast äquivalent, das stellte der Schreiber fest.

43. (a) Arbeitszeit und Vergnügen sind sicher ungleich, das suggerierte der Unterhalter.

(b) Unterhaltung und Vergnügen sind gewiss verwandt, das suggerierte der Unterhalter.

44. (a) Verachtung und Verehrung sind bestimmt verschieden, so vermutete die Dame.

(b) Ehrfurcht und Verehrung sind freilich entsprechend, so vermutete die Dame.

45. (a) Belobigung und Entwürdigung sind geradezu umgekehrt, das verteidigte die Soziologin.

(b) Erniedrigung und Entwürdigung sind ziemlich einheitlich, das verteidigte die Soziologin.

46. (a) Vergötterung und Nichtbeachtung sind geradezu umgekehrt, das zeigte die Nonne.

(b) Geringachtung und Nichtbeachtung sind ziemlich einheitlich, das zeigte die Nonne.

47. (a) Achtsamkeit und Zerstreutheit sind sicher ungleich, das teilte der Psychiater mit.

(b) Zerfahrenheit und Zerstreutheit sind gewiss verwandt, das teilte der Psychiater mit.

48. (a) Mittellosigkeit und Besitzlosigkeit sind sicher ungleich, so berichtigte der Wirtschafter.

(b) Wohlhabenheit und Besitzlosigkeit sind gewiss verwandt, so berichtigte der Wirtschafter. 


\section{Appendix B}

See Table B1.

Table B1

Results of the $2 \times 2$ repeated-measures ANOVA analyses for regions on which linear mixed-effect analyses resulted in an interaction effect $(d f 1=1$; $d f 2=45(46$ in Exp. 2) for F1; $d f 2=31$ for F2).

\begin{tabular}{|c|c|c|c|c|c|c|c|}
\hline Experiment & Region & Measure & Predictor & $F 1$ & $\eta^{2}$ & $F 2$ & $\eta^{2}$ \\
\hline \multirow[t]{12}{*}{ Experiment 1} & $\mathrm{ADJ}$ & First-pass & Similarity & $16.23^{* * *}$ & 0.344 & $8.960^{* *}$ & 0.166 \\
\hline & & & Distance & 1.834 & 0.044 & 0.280 & 0.006 \\
\hline & & & $\mathrm{S} \times \mathrm{D}$ & $3.604^{\#}$ & 0.105 & $7.529^{* * *}$ & 0.143 \\
\hline & VP2 & First-pass & Similarity & $3.181^{\#}$ & 0.084 & $5.488^{*}$ & 0.111 \\
\hline & & & Distance & 2.164 & 0.151 & 0.693 & 0.016 \\
\hline & & & $\mathrm{S} \times \mathrm{D}$ & $3.758^{\#}$ & 0.108 & $3.485^{\#}$ & 0.073 \\
\hline & NP3 & First-pass & Similarity & 0.145 & 0.005 & 1.162 & 0.025 \\
\hline & & & Distance & $7.698^{* *}$ & 0.199 & 1.335 & 0.029 \\
\hline & & & $\mathrm{S} \times \mathrm{D}$ & $4.531^{*}$ & 0.128 & $3.009^{\#}$ & 0.063 \\
\hline & NP3 & Total times & Similarity & 1.517 & 0.047 & 2.522 & 0.053 \\
\hline & & & Distance & $3.149^{\#}$ & 0.092 & 0.271 & 0.006 \\
\hline & & & $\mathrm{S} \times \mathrm{D}$ & $6.481^{*}$ & 0.173 & $3.306^{\#}$ & 0.068 \\
\hline \multirow[t]{6}{*}{ Experiment 2} & $\mathrm{ADJ}$ & Regression path & Similarity & $5.688^{\#}$ & .155 & $3.876^{\#}$ & .078 \\
\hline & & & Distance & 0.672 & .021 & 0.347 & .007 \\
\hline & & & $\mathrm{S} \times \mathrm{D}$ & $4.126^{\#}$ & .117 & $3.710^{\#}$ & .075 \\
\hline & ADJ & Total times & Similarity & $3.639^{*}$ & .105 & 1.174 & .025 \\
\hline & & & Distance & 2.641 & .079 & 1.284 & .027 \\
\hline & & & $\mathrm{S} \times \mathrm{D}$ & $7.752^{* *}$ & .200 & $4.904^{*}$ & .096 \\
\hline \multirow[t]{6}{*}{ Experiment 3} & NP2 & First-pass & Similarity & $15.020^{* * *}$ & 0.326 & 2.512 & 0.053 \\
\hline & & & Distance & 1.232 & 0.038 & 0.971 & 0.021 \\
\hline & & & $\mathrm{S} \times \mathrm{D}$ & 2.015 & 0.061 & $7.537^{* *}$ & 0.143 \\
\hline & VP2 & First-pass & Similarity & 0.018 & 0.001 & 0.098 & 0.002 \\
\hline & & & Distance & 0.142 & 0.005 & 0.018 & 0.000 \\
\hline & & & $\mathrm{S} \times \mathrm{D}$ & $4.757^{*}$ & 0.133 & 2.050 & 0.045 \\
\hline $\begin{array}{l}{ }^{*} p<0.1 \\
p<0.05 \\
p<0.01 \\
p<0.001\end{array}$ & & & & & & & \\
\hline
\end{tabular}

\section{Appendix C. Supplementary material}

Supplementary data associated with this article can be found, in the online version, at http://dx.doi.org/10.1016/ j.cognition.2014.07.007.

\section{References}

Allopenna, P. D., Magnuson, J. S., \& Tanenhaus, M. K. (1998). Tracking the time course of spoken word recognition using eye movements: Evidence for continuous mapping models. Journal of Memory and Language, 38, 419-439.

Altmann, G. T. M., \& Kamide, Y. (2009). Discourse-mediation of the mapping between language and the visual world: Eye-movements and mental representation. Cognition, 111, 55-71.

Anderson, J. R., \& Pirolli, P. L. (1984). Spread of activation. Journal of Experimental Psychology: Learning, Memory, and Cognition, 10, $791-798$.

Baayen, R. H. (2008). Analyzing linguistic data. A practical introduction to statistics using R. Cambridge, UK: Cambridge University Press.

Baayen, R. H., Davidson, D. J., \& Bates, D. M. (2008). Mixed-effects modeling with crossed random effects for subjects and items. Journal of Memory and Language, 59, 390-412.

Barr, D. J. (2008). Analyzing 'visual-world' eye-tracking data using multilevel logistic regression. Journal of Memory and Language, 59, 457-474.

Barr, D. J., Levy, R., Scheepers, C., \& Tily, H. J. (2013). Random-effects structure for confirmatory hypothesis testing: Keep it maximal. Journal of Memory and Language, 68, 255-278.
Bergen, B. K., Lindsay, S., Matlock, T., \& Narayanan, S. (2007). Spatial and linguistic aspects of visual imagery in sentence comprehension. Cognitive Science, 31, 733-764.

Boot, I., \& Pecher, D. (2010). Similarity is closeness: Metaphorical mapping in a conceptual task. Quarterly Journal of Experimental Psychology, 63, 942-954.

Carroll, P., \& Slowiaczek, M. L. (1986). Constraints on semantic priming in reading: A fixation time analysis. Memory \& Cognition, 14, 509-522.

Casasanto, D. (2008). Similarity and proximity: When does close in space mean close in mind? Memory \& Cognition, 36, 1047-1056.

Chambers, C. G., Tanenhaus, M. K., \& Magnuson, J. S. (2004). Actions and affordances in syntactic ambiguity resolution. Journal of Experimental Psychology: Learning, Memory and Cognition, 30, 687-696.

Collins, A. M., \& Loftus, E. F. (1975). A spreading-activation theory of semantic processing. Psychological Review, 82, 407-428.

Connell, L., \& Lynott, D. (2012). When does perception facilitate or interfere with conceptual processing? The effect of attentional modulation. Frontiers in Psychology, 3, 1-4.

Coppens, L. C., Gootjes, L., \& Zwaan, R. A. (2012). Incidental picture exposure affects later reading: Evidence from the N400. Brain and Language, 122, 64-69.

Crutch, S. J., \& Warrington, E. K. (2005). Abstract and concrete concepts have structurally different representational frameworks. Brain, 128, 615-627.

Dahan, D., \& Tanenhaus, M. K. (2005). Looking at the rope when looking for the snake: Conceptually mediated eye movements during spokenword recognition. Psychonomic Bulletin E Review, 12, 453-459.

Duñabeitia, J. A., Avilés, A., Afonso, O., Scheepers, C., \& Carreiras, M. (2009). Qualitative differences in the representation of abstract versus concrete words: Evidence from the visual-world paradigm. Cognition, 110, 284-292. 
Ferreira, F., Apel, J., \& Henderson, J. (2008). Taking a new look at looking at nothing. Trends in Cognitive Sciences, 12, 405-410.

Gallese, V., \& Lakoff, G. (2005). The brain's concepts: The role of the sensory-motor system in conceptual knowledge. Cognitive Neuropsychology, 22, 455-479.

Grady, J., \& Johnson, C. (1997). Converging evidence for the notions of subscene and primary scene. In Proceedings of the 23th annual meeting of the Berkeley Linguistics Society (pp. 123-136).

Guerra, E., \& Knoeferle, P. (2014). Spatial distance modulates reading times for sentence about social relations: Evidence from eye tracking. In P. Bello, M. Guarini, M. McShane, \& B. Scassellati (Eds.), Proceedings of the 36th anmual conference of the Cognitive Science Society (pp. 2315-2320). Austin, TX: Cognitive Science Society.

Hartsuiker, R. J., Huettig, F., \& Olivers, C. N. L. (Eds.). (2011). Visual search and visual world: Interactions among visual attention, language, and working memory. Acta Psychologica, 137, 135-260 [Special issue].

Huettig, F., \& Altmann, G. T. M. (2005). Word meaning and the control of eye fixation: Semantic competitor effects and the visual-world paradigm. Cognition, 96, B23-B32.

Huettig, F., \& Altmann, G. T. M. (2007). Visual-shape competition during language-mediated attention is based on lexical input and not modulated by contextual appropriateness. Visual Cognition, 15, 985-1018.

Huettig, F., \& Altmann, G. T. M. (2011). Looking at anything that is green when hearing 'frog': How object surface colour and stored object colour knowledge influence language-mediated overt attention. Quarterly Journal of Experimental Psychology, 64, 122-145.

Huettig, F., \& McQueen, J. M. (2007). The tug of war between phonological, semantic, and shape information in language-mediated visual search. Journal of Memory and Language, 54, 460-482.

Huettig, F., Quinlan, P. T., McDonald, S. A., \& Altmann, G. T. M. (2006). Models of high-dimensional semantic space predict languagemediated eye movements in the visual-world. Acta Psychologica, $121,65-80$.

Hutchison, K. A. (2003). Is semantic priming due to association strength or feature overlap? A microanalytic review. Psychonomic Bulletin \& Review, 10, 785-813.

Jacoby, L. L. (1983). Remembering the data: Analyzing interactive processes in reading. Journal of Verbal Learning and Verbal Behavior, 22, 485-508.

Johnson, C. (1999). Metaphor vs. conflation in the acquisition of polysemy: The case of see. In M. Hiraga, C. Sinha, \& S. Wilcox (Eds.), Amsterdam studies in the theory and history of linguistic science series 4. Philadelphia, PA: John Benjamins.

Kaschak, M. P., Madden, C. J., Therriault, D. J., Yaxley, R. H., Aveyard, M., Blanchard, A. A., et al. (2005). Perception of motion affects language processing. Cognition, 94, B79-B89.

Knoeferle, P., \& Crocker, M. W. (2006). The coordinated interplay of scene, utterance, and world knowledge: Evidence from eye tracking. Cognitive Science, 30, 481-529.

Knoeferle, P., \& Crocker, M. W. (2007). The influence of recent scene events on spoken comprehension: Evidence from eye movements. Journal of Memory and Language, 57, 519-543.

Knoeferle, P., Crocker, M. W., Scheepers, C., \& Pickering, M. J. (2005). The influence of the rapid visual context on incremental thematic roleassignment: Evidence from eye-movements in depicted events. Cognition, 95, 95-127.

Knoeferle, P., Urbach, T. P., \& Kutas, M. (2011). Comprehending how visual context influences incremental sentence processing: Insights from ERPs and picture-sentence verification. Psychophysiology, 48, 495-506.

Konieczny, L., Hemforth, B., Scheepers, C., \& Strube, G. (1997). The role of lexical heads in parsing: Evidence from German. Language and Cognitive Processes, 12, 307-348.

Lakoff, G., Espenson, J., \& Schwartz, A. (1991). Master metaphor list. Technical report. University of California at Berkeley.

Lakoff, G., \& Johnson, M. (1980). Metaphors we live by. Chicago, IL: University of Chicago Press.

Lakoff, G., \& Johnson, M. (1999). Philosophy in the flesh: The embodied mind and its challenge to western thought. New York, NY: Basic Books.

Liversedge, S. P., Paterson, K. B., \& Pickering, M. J. (1998). Eye movements and measures of reading time. In G. Underwood (Ed.), Eye guidance in reading and scene perception. Oxford, UK: Elsevier.
Mahon, B. Z., \& Caramazza, A. (2008). A critical look at the embodied cognition hypothesis and a new proposal for grounding conceptual content. Journal of Physiology - Paris, 102, 59-70.

Meteyard, L., Zokaei, N., Bahrami, B., \& Vigliocco, G. (2008). Visual motion interferes with lexical decision on motion words. Current Biology, 18, R732-R733.

Meyer, D. E., \& Schvaneveldt, R. W. (1971). Facilitation in recognizing pairs of words: Evidence of a dependence between retrieval operations. Journal of Experimental Psychology, 90, 227.

Mirman, D., \& Magnuson, J. S. (2009). Dynamics of activation of semantically similar concepts during spoken word recognition. Memory \& Cognition, 37, 1026-1039.

Morris, R. K. (1994). Lexical and message-level sentence context effects on fixation times in reading. Journal of Experimental Psychology: Learning, Memory, and Cognition, 20, 92-103.

Paivio, A. (1986). Mental representations: A dual coding approach. New York, NY: Oxford University Press.

Paivio, A. (2013). Dual coding theory, word abstractness, and emotion: A critical review of Kousta et al. (2011). Journal of Experimental Psychology: General, 142, 282-287.

Pecher, D., van Dantzig, S., Zwaan, R. A., \& Zeelenberg, R. (2009). Language comprehenders retain implied shape and orientation of objects. Quarterly Journal of Experimental Psychology, 62, 1108-1114.

Quené, H., \& van den Bergh, H. (2004). On multi-level modeling of data from repeated measures designs: A tutorial. Speech Communication, $43,103-121$.

Quené, H., \& van den Bergh, H. (2008). Examples of mixed-effects modeling with crossed random effects and with binomial data. Journal of Memory and Language, 59, 413-425.

Rayner, K. (1998). Eye movements in reading and information processing: 20 years of research. Psychological Bulletin, 124, 372-422.

Rayner, K., \& Liversedge, S. P. (2004). Visual and linguistic processing during eye fixation in reading. In J. M. Henderson \& F. Ferreira (Eds.), The interface of language, vision, and action: Eye movements and the visual world. New York, NY: Psychology Press.

Richardson, D. C., Altmann, G. T. M., Spivey, M. J., \& Hoover, M. A. (2009). Much ado about eye movements to nothing: A response to Ferreira et al.: Taking a new look at looking at nothing. Trend in Cognitive Sciences, 13, 235-236.

Richardson, D. C., Spivey, M. J., Barsalou, L. W., \& McRae, K. (2003). Spatial representations activated during real-time comprehension of verbs. Cognitive Science, 27, 767-780.

Sedivy, J. E., Tanenhaus, M. K., Chambers, C. G., \& Carlson, G. N. (1999). Achieving incremental interpretation through contextual representation: Evidence from the processing of adjectives. Cognition, 71, 109-147.

Stanfield, R. A., \& Zwaan, R. A. (2001). The effect of implied orientation derived from verbal context on picture recognition. Psychological Science, 12, 153-156.

Sturt, P., Keller, F., \& Dubey, A. (2010). Syntactic priming in comprehension: Parallelism effects with and without coordination. Journal of Memory and Language, 62, 333-351.

Tabachnik, B., \& Fidell, L. S. (2007). Experimental design using ANOVA. Belmont, CA: Duxbury.

Tanenhaus, M. K., Magnuson, J. S., Dahan, D., \& Chambers, C. (2000). Eye movements and lexical access in spoken-language comprehension: Evaluating a linking hypothesis between fixations and linguistic processing. Journal of Psycholinguistic Research, 29, 557-580.

Tanenhaus, M. K., Spivey-Knowlton, M. J., Eberhard, K. M., \& Sedivy, J. C. (1995). Integration of visual and linguistic information in spoken language comprehension. Science, 268, 1632-1634.

Traxler, M. J., Pickering, M. J., \& Clifton, C. (1998). Adjunct attachment is not a form of lexical ambiguity resolution. Journal of Memory and Language, 39, 558-592.

Wassenburg, S. I., \& Zwaan, R. A. (2010). Readers routinely represent implied object rotation: The role of visual experience. Quarterly Journal of Experimental Psychology, 63, 1665-1670.

Zwaan, R. A., Stanfield, R. A., \& Yaxley, R. H. (2002). Language comprehenders mentally represent the shapes of objects. Psychological Science, 13, 168-171. 